\title{
HOÀN THIỆN QUY ĐỊNH TRONG DỰ THẢO SỦA ĐỔI BỔ SUNG LUẬT DOANH NGHIỆP 2014 VỀ VÁN ĐỀ THÀNH LẬP DOANH NGHIỆP
}

\author{
HỒ XUÂN THẮNG \\ Khoa Luật Kinh tế, Trường Đại học Ngân hàng thành phố Hồ Chí Minh \\ thanghx@buh.edu.vn
}

Tóm Tắt: Khi so sánh về thủ tục thành lập doanh nghiệp Ngân hàng thế giới đã nhận định: Trong năm 2019, nước ta được xếp hạng thứ 104 trên 190 quốc gia và nền kinh tế. Với thực trạng đó, việc đòi hỏi cải cách thể chế pháp lý là rất cấp bách, đặt lên hàng đầu để cắt giảm những thủ tục không cần thiết nhằm rút ngắn thời gian và giảm chi phí cho nhà đầu tư là doanh nhân và thương nhân Do vậy, Thực hiện Nghị quyết số 57/2018/QH14 ngày 8/6/2018 của Quốc hội về Chương trình xây dựng luật, pháp lệnh năm 2019, điều chỉnh Chương trình xây dựng luật, pháp lệnh năm 2018 và Quyết định số 792/QĐ-TTg ngày 28/6/2018 của Thủ tướng Chính phủ, Bộ Kế hoạch và Đầu tư đã tổ chức thực hiện Dự án Luật Doanh nghiệp (sửa đổi). Dự thảo lần thứ ba của Luật cũng đã được được đăng tải và cập nhật trên Cổng thông tin điện tử của Chính phủ và Bộ Kế hoạch và Đầu tư để lấy ý kiến của các đối tượng có liên quan. Cụ thể như: lấy ý kiến bằng văn bản của các Bộ, ngành, địa phương, doanh nghiệp, tổ chức hội thảo lấy ý kiến của các nhà khoa học, làm việc trực tiếp với một số Bộ, ngành, địa phương, doanh nghiệp về dự thảo Luật.

Bài viết này, Tác giả tập trung phân tích một số nội dung quy định về thành lập doanh nghiệp còn bất cập chưa phù hợp với thực tiễn. Đồng thời đưa ra những kiến nghị góp phần hoàn thiện hơn khung khổ pháp lý của Luật doanh nghiệp sủa đổi làm cơ sở điều chỉnh đáp ứng nhu cầu thành lập doanh nghiệp phục vụ tốt hơn hoạt động kinh doanh của các chủ thể kinh trong nền kinh tế thị trường nhiều thành phần theo định hướng xã hội chủ nghĩa ở nước ta để cùng nhau trao đổi.

Tù̀ khóa: Góp ý sửa đổi về thành lập doanh nghiệp trong dự thảo luật doanh nghiệp; Cải cách chế định thành lập doanh nghiệp và một số kiến nghị hoàn thiện.

\section{COMPLETING REGULATIONS IN THE 2014 AMENDING AND SUPPLEMENTING THE LAW ON ENTERPRISES 'ADDITIONAL PROBLEMS}

Summary. When comparing the procedures for establishing a World Bank enterprise, it has been identified: In 2019, our country is ranked 104th out of 190 countries and economies. Given that situation, the need for legal institutional reform is very urgent, putting on top to cut unnecessary procedures to reduce time and reduce costs for investors who are entrepreneurs and traders. Therefore, Implement the Resolution No. 57/2018 / QH14 dated June 8, 2018 of the National Assembly on the law and ordinance making program in 2019, adjusting the law and ordinance making program in 2018 and the Decision No. 792 / QD-TTg dated June 28, 2018 of the Prime Minister, Ministry of Planning and Investment organized the implementation of the Enterprise Law Project (amended). The third draft of the Law has also been posted and updated on the Government Web Portal and the Ministry of Planning and Investment for comments from relevant stakeholders. Specifically: collecting opinions in writing of ministries, branches, localities, enterprises, organizing seminars to collect opinions of scientists, working directly with a number of ministries, branches, localities and enterprises. career on the draft law.

In this article, the author focuses on analyzing a number of contents of regulations on establishment of enterprises which are still inadequate. At the same time, making recommendations to improve the legal framework of the amended Enterprise Law as a basis for adjusting to meet the needs of enterprise establishment to better serve the business activities of business entities in the background. Socialist-oriented market economy with many components in our country for mutual exchange.

Keywords: Comment on amendments on enterprise establishment in the enterprise law draft; 


\section{VỀ VẤN ĐỀ VỐN ĐIỀU LỆ}

\section{Nhận diện về vấn đề vốn điều lệ, như sau:}

Tại khoản 29 điều 4 dự thảo sửa đồi có quy định: "Vốn điều lệ là tổng giá trị tài sản do các thành viên đã góp hoặc cam kết góp khi thành lập công ty trách nhiệm hữu hạn, công ty hợp danh; là tổng mệnh giá cổ phần đã bán hoặc đã được đăng ký mua khi thành lập doanh nghiệp đối với công ty cổ phần"

Nhìn nhận theo khoa học pháp lý thì quy định như thế nó còn rất bất cập, mâu thuẫn với chính nội tại các nội dung có liên quan đến vốn điều lệ trong dự thảo sửa đổi này. Vốn điều lệ trong dự thảo nêu rõ việc hiểu cũng như điều chỉnh nó chỉ có trong bốn loại công ty (TNHH 1 TV; Công ty TNHH 2 TV trở lên; Công ty Hợp danh; Công ty $\mathrm{CP}$ ) chứ không có điều chỉnh cho loại doanh nghiệp tư nhân hoặc là hộ kinh doanh. Nghĩa là vốn điều lệ của một công ty xuất hiện khi thành lập công ty, không thành lập công ty thì vồn điều lệ không hình thành. Tiếp theo, đó là tổng giá trị tài sản của công ty đó do người thành lập công ty góp vào. Ví dụ như công ty TNHH TM-DV Châu Sa khi thành lập doanh nghiệp này có vốn điều lệ là 40 tỷ VNĐ. Vốn 40 tỷ đó là do 3 thành viên công ty góp: Lê Thị KIều Sa góp 10 tỷ(10.000.000.000); Nguyễn Anh Châu góp 15 tỷ (15.000.000.000); Chu Thị Miện góp 10 tỷ (10.000.000.000). Tài sản các thành viên góp vào công ty này là đồng tiền Việt Nam vàdượcđược cơ quan nhà nước có thẩm quyền cấp giấy chứng nhận đăng ký thành lập.

Tuy nhiên, khái niệm công ty TNHH tại khoản 4 điều 4 của dự thảo được hiểu "Công ty TNHH bao gồm công ty trách nhiệm hữu hạn một thành viên và công ty trách nhiệm hữu hạn hai thành viên trở lên.". Tại khoản 1 điều 73 của dự thảo đưa ra khái niệm lại không tương thích với quy định về khái niệm vốn điều lệ nói trên đây, cụ thể là: “ Công ty trách nhiệm hữu hạn một thành viên là doanh nghiệp do một tổ chức hoặc một cá nhân làm chủ sở hữu (sau đây gọi là chủ sở hữu công ty); chủ sở hữu công ty chịu trách nhiệm về các khoản nợ và nghĩa vụ tài sản khác của công ty trong phạm vi số vốn điều lệ của công ty”. Ví dụ Công ty TNHH một thành viên Hoa Mai có vốn điều lệ là 10.000.000.000 VNĐ (10 tỷ VNĐ) do Chị Lưu Thị Mai Hoa góp vào. Đây là công ty TNHH một thành viên là cá nhân do Chị Mai Hoa làm chủ sở hữu vốn điều lệ. Như vậy, vì dụ này khẳng định không trùng khớp với khái niệm "Vốn điều lệ, do các thành viên công ty góp". Khi sử dụng cụm từ "Các thành viên" mặc nhiên ta hiểu đó phải từ 2 thành viên đến rất nhiều thành viên chứ không thể là "một thành viên".

Điều đáng nói là quy định khoản 29 điều 4 dự thảo rất bất cập mâu thuẫn với cả doanh nghiệp tư nhân, hộ kinh doanh chứ không chỉ với loại hình công ty TNHH một thành viên là tổ chức hoặc cá nhân làm chủ sở hữu công ty. Như đã phân tích trên đây, khái niệm vốn điều lệ loại khỏi sự điều chỉnh của nó là doanh nghiệp tư nhân do một cá nhân làm chủ và hộ kinh doanh do một cá nhân hoặc một nhóm người hoạt động. Trong quy định về nội dung Giấy chứng nhận đăng ký doanh nghiệp tại điều 29 của dự thảo, có các nội dung bao gồm:

1. Tên doanh nghiệp và mã số doanh nghiệp.

2. Địa chỉ trụ sở chính của doanh nghiệp.

3. Họ, tên, địa chỉ thường trú, quốc tịch, số Thẻ căn cước công dân, Giấy chứng minh nhân dân, Hộ chiếu hoặc chứng thực cá nhân hợp pháp khác của người đại diện theo pháp luật của doanh nghiệp đối với công ty trách nhiệm hữu hạn và công ty cổ phần; của các thành viên hợp danh đối với công ty hợp danh; của chủ doanh nghiệp đối với doanh nghiệp tư nhân; họ, tên, địa chỉ thường trú, quốc tịch, số Thẻ căn cước công dân, Giấy chứng minh nhân dân, Hộ chiếu hoặc chứng thực cá nhân hợp pháp khác của thành viên là cá nhân; tên, mã số doanh nghiệp và địa chỉ trụ sở chính của thành viên là tổ chức đối với công ty trách nhiệm hữu hạn.

4. Vốn điều lệ.

Theo chúng tôi hiểu tất cả các các đối tượng quy định tại khoản 1 điều 2 của dự thảo đó chính là "Các doanh nghiệp, hộ kinh doanh." đều được cấp giấy chứng nhận đăng ký thành lập. Tức là trong giấy chúng nhận đăng ký kinh doanh của doanh nghiệp, sẽ có nội dung thứ tư là vốn điều lệ. Với lập luận như vậy rõ ràng khái niệm vốn điều lệ tại khoản 29 điều 4 dự thảo mà các nhà làm luật đưa ra chưa phù hợpvới khoa học và thực tiễn.

Một điểm rất bất hợp lý là trong khái niệm các nhà làm luật sử dụng cụm từ "các thành viên" thì rất phiến diện không đại diện hết cho cách hiểu đối tượng điều chỉnh là doanh nghiệp) Công ty TNHH 1 TV; TNHH 2 TV trở lên; Hợp danh; Cổ phần và DNTN" trong dự thảo sửa đổi lần này. Để thống nhất với khái niệm 
góp vốn quy định tại khoản 13 điều 4 trên đây thì không nên sử dụng cụm từ "các thành viên" mà nên thay thế vào đó là cụm từ "người góp vốn" thì khoa học hơn và phù hợp với đối tượng áp dụng của luật doanh nghiệp mà chúng ta đang sửa đổi bổ sung lần này.

\section{Kiến nghị:}

Để thống nhất chung từ trung ương đến địa phương khi áp dụng quy định của pháp luật về "vốn điều lệ" cũng như phù hợp với các nội dung liên quan đến vốn pháp định của các chủ thể kinh doanh cũng như các cơ quan cấp giấy chứng nhận đăng ký thành lập quy định trong dự thảo này, chúng tôi kiến nghị ban soạn thảo lưu ý sửa lại khái niệm "Vốn điều lệ" tại khoản 29 điều 4 của dự thảo, như sau:

"Vốn điều lệ là tổng giá trị tài sản do người góp vốn đã góp hoặc cam kết góp khi thành lập công ty trách nhiệm hữu hạn, công ty hợp danh; doanh nghiệp tư nhân; là tổng mệnh giá cổ phần đã bán hoặc đã được đăng ký mua khi thành lập doanh nghiệp đối với công ty cổ phần"

Ngoài ra, Ban soạn thảo cũng cần xem xét tính phù hợp trong quy định về vốn điều lệ phải thống nhất chung trong nội dung Giấy chứng nhận đăng ký doanh nghiệp tại điều 29 với nội dung giấy đề nghị đăng ký doanh nghiệp tại điều 24 của dự thảo "Vốn điều lệ; vốn đầu tư của chủ doanh nghiệp tư nhân." Nghĩa là tại khoản 4 điều 24 nên giữ nguyên cụm từ "Vốn điều lệ" để áp dụng cho tất cả các dối tượng áp dụng của Luật Doanh nghiệp quy định tại điều 2 , bỏ cụm từ "vốn đầu tư của chủ doanh nghiệp tư nhân" Bởi vì, vốn đầu tư chi được sử dụng trong trường hợp các nhà đầu tư thực hiện dự án đầu tư theo Luật đầu tư điều chỉnh chứ doanh nghiệp tư nhân do một cá nhân làm chủ không thể có những dự án mang tầm cỡ Chính phủ phê duyệt hoặc Chủ tịch ủy ban nhân dân cấp tỉnh thành phê duyệt. Mặt khác, Chủ doanh nghiệp tư nhân cũng phải thống nhất chung trong lý luận luật kinh doanh họ là người góp vốn để kinh doanh nhằm mục đích sinh lời như các loại hình doanh nghiệp khác trong nền kinh tế thị trường ở nước ta.

\section{QUYỀn THÀNH LẬP, GÓP VỐN, MUA CỔ PHẦn, MUA PHẦN VỐN GÓP CỦA DOANH NGHIÊP.}

\section{Nhận định của Tác giả về vấn đề này:}

Theo quy định tại tại khoản 3 điều 18 Luật Doanh nghiệp 2014 thì quyền thành lập, góp vốn, mua cổ phần, mua phần vốn góp và quản lý doanh nghiệp được quy định cụ thể như sau:

Tổ chức, cá nhân có quyền góp vốn, mua cổ phần, mua phần vốn góp vào công ty cổ phần, công ty trách nhiệm hữu hạn, công ty hợp danh theo quy định của Luật này.

Tức là tại quy phạm này, pháp luật cho phép mọi tổ chức cá nhân đều được quyền góp vốn, mua cổ phần, mua phần vốn góp vào công ty. Điều này thể hiện rõ sự bình đẳng của pháp luật trong việc thực hiện quyền góp vốn, mua cổ phần, mua phần vốn góp vào các công ty trong nền kinh tế thị trường ở nước ta.

Tuy nhiên trong quy phạm này, Ban soạn thảo xây dựng hai nhóm tổ chức, cá nhân không có quyền này bằng một cụm từ "trừ trường hợp sau đây". Nghĩa là, các trường hợp như: a) Cơ quan nhà nước, đơn vị vũ trang nhân dân sử dụng tài sản nhà nước góp vốn vào doanh nghiệp để thu lợi riêng cho cơ quan, đơn vị mình; b) Các đối tượng không được góp vốn vào doanh nghiệp theo quy định của luật về cán bộ, công chức". thì không được quyền góp vốn, mua cổ phần, mua phần vốn góp vào công ty. Như vậy, về tổng quan quyền góp vốn, mua cố phần, mua phần vốn góp vào công ty trong chế định này cho ta thấy rất rộng rãi và công bằng minh bạch cho tất cả mọi tổ chwucs, cá nhân. Ngoài ra ở dạng hẹp hưn thì chế định này hạn chế cái quyền góp vốn, mua cổ phần, mua phần vốn góp vào công ty với hai nhóm đối tượng rất cụ thể đó là i) Cơ quan nhà nước, đơn vị vũ trang nhân dân sử dụng tài sản nhà nước góp vốn vào doanh nghiệp để thu lợi riêng cho cơ quan, đơn vị mình; ii) Các đối tượng không được góp vốn vào doanh nghiệp theo quy định của luật về cán bộ, công chức.

Nhìn nhận theo góc độ khoa học pháp lý thì quy định này chưa đồng bộ và hợp lý khoa học với các chế định khác trong quy định mà Luật doanh nghiệp này điều chỉnh.

Nói về "tổ chức là doanh nghiệp" trong văn bản luật này chúng tôi đồng ý với cách đặt vấn đề tại khoản 7 điều 4 "Doanh nghiệp là tổ chức có tên riêng, có tài sản, có trụ sở giao dịch, được đăng ký thành lập theo quy định của pháp luật nhằm mục đích kinh doanh". Tại khoản 1 điều 47 quy định về công ty TNHH 2 thành viên trở lên, Khoản 1 điều 73 quy định về công ty TNHH 1 thành viên. Khoản 1 điều 110 quy định về công ty công ty Cổ phần. khoản 1 điều 172 quy định về công ty Hợp danh và khoản 1 điều 183 quy định về DNTN đều thừa nhận họ là doanh nghiệp, nghĩa là họ chính là tổ chức thuộc phạm vi điều chỉnh của khoản 3 điều 18 luật này. Như vậy tại khoản 1 điều 183 thừa nhận doanh nghiệp tư nhân là doanh nghiệp 
do một cá nhân làm chủ thì doanh nghiệp tư nhân được thừa nhận là một tổ chức có quyền góp vốn, mua cổ phần, mua phần vốn góp vào công ty cổ phần, công ty trách nhiệm hữu hạn, công ty hợp danh theo quy định của Luật này. Mặt khác, doanh nghiệp tư nhân không thuộc tổ chức bị loại trừ quyền trong quy định ở điểm a và $b$ của khoản 3 điều 18 nói trên đây. Do vậy, quy định tại khoản 4 điều 183 "Doanh nghiệp tư nhân không được quyền góp vốn thành lập hoặc mua cổ phần, phần vốn góp trong công ty hợp danh, công ty trách nhiệm hữu hạn hoặc công ty cổ phần" rất mâu thuẫn với quy định tại khoản 3 điều 18 luật này. Khi doanh nghiệp tư nhân không thuộc đối tượng bị cầm tại khoản 3 điều 18 thì không có cơ sở để Ban soạn thảo cấm tổ chức này quyền góp vốn, mua cổ phần, mua phần vốn góp vào công ty. Nghĩa là tại khoản 3 điều 18 chỉ giới hạn hai nhóm bị hạn chế quyền nêu trên đó là i) Cơ quan nhà nước, đơn vị vũ trang nhân dân sử dụng tài sản nhà nước góp vốn vào doanh nghiệp để thu lợi riêng cho cơ quan, đơn vị mình; ii) Các đối tượng không được góp vốn vào doanh nghiệp theo quy định của luật về cán bộ, công chức . Tại sao lại quy định này được xây dựng cấm đoán cho DNTN tại khoản 4 điều 183 trong khi đó DNTN đang mang bản chất là một tổ chức?. Có thể thấy rằng quy định này đang rất mâu thuẫn với nội tại của nó, làm giảm giá trị pháp lý áp dụng chung thống nhất từ trung ương đến địa phương trong suốt một thời gian khá dài kể từ ngày luật doanh nghiệp 2014 có hiệu lực thi hành.

\section{Kiến nghị:}

Để khoa học hơn và thống nhất nội dung trong quy định về được quyền và cấm có quyền góp vốn thành lập hoặc mua cổ phần, phần vốn góp trong công ty hợp danh, công ty trách nhiệm hữu hạn hoặc công ty cổ phẩn. Chúng tôi đề nghị Ban soạn thảo bổ sung nhóm đối tượng Doanh nghiệp tư nhân cũng thuộc phạm vi điều chỉnh không được quyền như đã nêu trên để phù hợp hơn với quy định tại khoản 4 điều 183 , cụ thể: “3. Tổ chức, cá nhân có quyền góp vốn, mua cổ phần, mua phần vốn góp vào công ty cổ phần, công ty trách nhiệm hữu hạn, công ty hợp danh theo quy định của Luật này, trừ trường hợp sau đây: Doanh nghiệp tư nhân không được quyền góp vốn thành lập hoặc mua cổ phần, phần vốn góp trong công ty hợp danh, công ty trách nhiệm hữu hạn hoặc công ty cổ phần.

a) Cơ quan nhà nước, đơn vị vũ trang nhân dân sử dụng tài sản nhà nước góp vốn vào doanh nghiệp để thu lợi riêng cho cơ quan, đơn vị mình;

b) Các đối tượng không được góp vốn vào doanh nghiệp theo quy định của luật về cán bộ, công chức.

c) Doanh nghiệp tư nhân do một cá nhân làm chư"

\section{II.VỀ QUẢN LÝ CON DẤU CỦA DOANH NGHIỆP}

\section{Quan điểm nhận định của Tác giả về vấn đề này như sau:}

Tại Điều 44 của dự thảo có quy định về Con dấu của doanh nghiệp, như sau:

“1. Doanh nghiệp có quyền quyết định có hoặc không có con dấu; quyết định loại dấu, số lượng, hình thức và và nội dung con dấu của doanh nghiệp, dấu của chi nhánh, văn phòng đại diện và đơn vị khác của doanh nghiệp. Việc quản lý, sử dụng và lưu giữ con dấu thực hiện theo quy định của Điều lệ công ty hoặc quy chế doanh nghiệp, đơn vị khác của doanh nghiệp ban hành".

Thực tiễn trong quá trình tham gia góp ý kiến về vấn đề này đã có 2 luồng ý kiến góp ý khác nhau . Nhóm ý kiến thứ nhất: Nhiều ý kiến đồng tình với quy định con dấu trong dự thảo Luật, cần trao quyền cho doanh nghiệp tự quyết định xem có hay không việc sử dụng con dấu; bãi bỏ thủ tục thông báo mẫu dấu là giảm chi phí cho doanh nghiệp, cần sử dụng chữ ký điện tử thay cho con dấu. Nhóm ý kiển thứ hai: Đề nghị duy trì quy định con dấu như quy định hiện hành để phù hợp với đặc điểm tình hình của nước ta; không nên bỏ dấu vì đây là phương tiện để giao dịch, đề nghị cân nhắc để tránh phát sinh bất tiện và ràng buộc pháp lý cho doanh nghiệp.

Nhìn nhận theo góc độ nguyên tắc, mục tiêu sửa đổi Luật doanh nghiệp lần này, Chúng tôi nhận thấy: Một trong những nội dung thay đổi cơ bản phù hợp với thực tiễn của Luật Doanh nghiệp 2014 đạt được so với Luật Doanh nghiệp năm 2005 là quy định về quản lý và sử dụng dấu của doanh nghiệp. Theo đó, cơ chế phải có một cơ quan quản lý nhà nước đại diện thẩm quyền cấp dẩu cho doanh nghiệp đã được chuyển sang cơ chế doanh nghiệp tự làm dấu và tự quản lý việc sử dụng dấu của mình. Tức là Doanh nghiệp có quyền tự quyết định sổ lượng con dấu, hình thức mẫu dấu, phương thức quản lý và sử dụng dấu; tự quyết định sử dụng dấu trong giao dịch dân sự. Thực tế cũng đã chứng minh cho việc thay đổi trên đã được cộng đồng 
doanh nghiệp đánh giá tích cực, vởi vì điều đó đã thực sự xóa bỏ được nhiều bất cập trước đây trong quản lý con dẩu của doanh nghiệp, như: tranh chấp nội bộ trong doanh nghiệp bị kéo dài và không thể giải quyết dứt điểm do con dấu bị chiếm giữ bởi một bên; giảm thiểu việc "lạm dụng" dấu dẫn đến giao dịch kinh doanh kém an toàn, thiếu tính khả thi do các bên bỏ qua việc nghiên cứu, tìm hiểu năng lực đối tác khi ký hợp đồng, mà chỉ đơn thuần dựa vào việc đóng dấu...

Đối với sửa đổi quy định về dấu doanh nghiệp tại Điều 44 trong dự thảo Luật, Chúng tôi hoàn toàn đồng ý với nhóm ý kiến thứ nhất nêu trên đây. Nghĩa là không đồng ý với ý kiến thứ hai về việc giữ nguyên nội dung quy định về con dấu tại điều 44 trong Luật doanh nghiệp 2014. ban soạn thảo đã bãi bỏ quy định về thủ tục thông báo mẫu dấu cho cơ quan đăng ký kinh doanh. Như vậy, sửa đổi này các nhà làm luật không bãi bỏ hoàn toàn việc sử dụng dấu của doanh nghiệp mà chỉ tiếp tục khẳng định quyền tự quyết có hoặc không có con dấu thuộc về nội bộ của doanh nghiệp, quyết định sử dụng con dấu hoặc phương tiện điện tử khác thay thế ví dụ như chữ ký điện tử của người địa diện theo pháp luật cho phù hợp với tính chất kinh doanh và mong muốn của nhà đầu tư, doanh nghiệp.

Ngoài ra, việc bãi bỏ thủ tục thông báo mẫu dấu quy định trong khoản 2 điều 44 Luật doanh nghiệp 2014, không chỉ có ý nghĩa trong việc că̆t giảm chi phí không cần thiết mà còn giúp doanh nghiệp ý thức rõ ràng hơn trong việc sử dụng con dấu, gia tăng độ an toàn trong giao dịch kinh doanh, hội nhập tốt hơn vào thị trường quốc tế.

Tuy nhiên, nhìn nhận theo góc độ kỹ thuật lập pháp, Ban soạn thảo đưa ra cấu trúc của điều 44 trong dự thảo chưa hợp lý, nội dung thì chưa chặt chẽ, không thể làm quy tắc xử sử áp dụng chung thống nhất trong thực tiễn. Chúng tôi rất lo ngại về việc thiếu nhất quán trong nội dung và cách xây dựng chế định hẹp trong một quy phạm tại điều 44 của dự thảo về con dấu và quản lý con dấu của doanh nghiệp.

\section{Kiến nghị:}

Để khoa học hơn trong một quy phạm cho phép, Ban soạn thảo cần xử lý nội dung rõ ràng và hợp lý, cần phân định nội dung theo 3 khoản riêng biệt để nội dung quy định tại điều 44 của dự thảo về con dấu và quản lý con dấu của doanh nghiệp trong dự thảo dễ áp dụng hơn trong thực tiễn khi được Quốc hội đồng ý thông qua, như sau.

“1. Doanh nghiệp có quyền quyết định có hoặc không có con dấu của doanh nghiệp, dấu của chi nhánh, văn phòng đại diện và đơn vị trực thuộc khác của doanh nghiệp.

2. Doanh nghiệp tự quyết định loại dấu, số lượng, hình thức và nội dung con dấu phù hợp với doanh nghiệp, chi nhành, văn phòng đại diện và đơn vị trực thuộc khác của doanh nghiệp.

3. Việc quản lý, sử dụng và lưu giữ con dấu thực hiện theo quy định của Điều lệ công ty hoặc quy chế doanh nghiệp, đơn vị trực thuộc khác của doanh nghiệp ban hành”.

\section{VÁN ĐỀ CÁC HÀNH VI BỊ CÁM}

\section{Các hành vi bị cấm theo nhận định của Tác giả:}

Vấn đề này ban soạn thảo giữ nguyên 7 khoản riêng biệt tại điều 17 Luật doanh nghiệp 2015, thể hiện tính phù hợp của quy định này trong thực tiễn thi hành pháp luật doanh nghiệp suốt thời gian qua ở nước ta. Các hành vi bị nghiêm cấm, bao gồm:

1. Cấp hoặc từ chối cấp Giấy chứng nhận đăng ký doanh nghiệp, yêu cầu người thành lập doanh nghiệp nộp thêm giấy tờ khác trái với quy định của Luật này; gây chậm trễ, phiền hà, cản trở, sách nhiễu người thành lập doanh nghiệp và hoạt động kinh doanh của doanh nghiệp.

2. Ngăn cản chủ sở hữu, thành viên, cổ đông của doanh nghiệp thực hiện các quyền, nghĩa vụ theo quy định của Luật này và Điều lệ công ty.

3. Hoạt động kinh doanh dưới hình thức doanh nghiệp mà không đăng ký hoặc tiếp tục kinh doanh khi đã bị thu hồi Giấy chứng nhận đăng ký doanh nghiệp.

4. Kê khai không trung thực, không chính xác nội dung hồ sơ đăng ký doanh nghiệp và nội dung hồ sơ đăng ký thay đổi nội dung đăng ký doanh nghiệp.

5. Kê khai khống vốn điều lệ, không góp đủ số vốn điều lệ như đã đăng ký; cố ý định giá tài sản góp vốn không đúng giá trị.

6. Kinh doanh các ngành, nghề cấm đầu tư kinh doanh; kinh doanh ngành, nghề đầu tư kinh doanh có điều kiện khi chưa đủ các điều kiện kinh doanh theo quy định của Luật Đầu tư hoặc không bảo đảm duy trì đủ điều kiện kinh doanh trong quá trình hoạt động. 
7. Rửa tiền, lừa đảo, tài trợ khủng bố.

Chúng tôi cũng đồng ý với cách tiếp cận chuyển tiếp nội dung quy định này ở văn bản Luật doanh nghiệp 2015 vào nội dung sửa đổi với ý chí là không bãi bỏ nội dung các hành vi bị cấm trong việc thành lập doanh nghiệp và quản lý doanh nghiệp. Tuy nhiên, khi nghiên cứu sâu vào 7 vấn đề bị cấm trong quy phạm này thì còn có những vấn đề chưa được rõ ràng, chồng chéo khó thực hiện thống nhất trong tương lai khi dự thảo luật doanh nghiệp này được Quố hội thông qua, cụ thể là

Tại khoản 4, có quy định cấm chủ thể kinh doanh "Kê khai không trung thực, không chính xác nội dung hồ sơ đăng ký doanh nghiệp và nội dung hồ sơ đăng ký thay đổi nội dung đăng ký doanh nghiệp". Việc kê khai nêu trên đây là trong trường hợp doanh nghiệp thực hiện quyền của mình khi hình thành một pháp nhân hay thể nhân hay là thay đổi nội dung đã hình thành một pháp nhân hay thể nhân thông qua hình thức tự mình hoặc thông qua người đại diện nộp hồ sơ thành lập tại cơ quan đăng ký kinh doanh nhà nước có thẩm quyền . Câu hỏi đặt ra là khi người đi đăng ký thành lập hoặc thay đổi nội dung đăng ký doanh nghiệp có hồ sơ kê khai không trung thực tại khoản 5 , liệu doanh nghiệp có hành vi“ "Kê khai khống vốn điều lệ" không? Hoặc là hành vi "kê khai khống vốn điều lệ" có thuộc về hành vi Kê khai không trung thực, không chính xác nội dung hồ sơ đăng ký doanh nghiệp và nội dung hồ sơ đăng ký thay đổi nội dung đăng ký doanh nghiệp không?.

Theo nghiên cứu của chúng tôi, hành vi bị cầm "kê khai khống vốn điều lệ" quy định tại khoản 5 điều 17 trong dự thảo trùng với hành vi bị cấm "Kê khai không trung thực, không chính xác.". Thông thường việc kê khai khống vốn điều lệ là việc làm có chủ ý của chủ thể kinh doanh thể hiện trong các biên bản góp vốn trước khi họ thực hiện hoạt động kinh doanh. Nghĩa là mục đích kê khai khống vốn để hoàn thiện bộ hồ sơ đăng ký kinh doanh với cơ quan nhà nước có thẩm quyền theo luật định. Do đó, hành vi kê khai khống vốn điều lệ là tương đồng với hành vi kê khai không trung thực, không chính xác của chủ thể kinh doanh. Như vậy, việc cấm đoán chủ thể kinh doanh không được có hành động kê khai khống vốn điều lệ, bởi vì kê khai khống tức là kê khai không trung thực. Tại điều 24 của dự thảo có quy định về "Nội dung giấy đề nghị đăng ký doanh nghiệp" thì người đi đăng ký kinh doanh pháp thống nhất các nội dung trong giấy đề nghị đăng lý, đặc biệt là ghi rõ nội dung tại khoản 4 "Vốn điều lệ; vốn đầu tư của chủ doanh nghiệp tư nhân". Theo chúng tôi hiểu là tại nội dung giấy đề nghị chủ thể kinh doanh phải điền đầy đủ nội dung quy định trong 9 khoản của điều 24, trong đo kê khai khống vốn điều lệ quy định tại khoản 4 là hành vi bị cấm như đã phân tích trên đây

\section{Kiến nghị:}

Để phù hợp hơn với khoa học cũng như thực tiễn, các nhà làm luật cần cân nhắc xem xét quy định các hành vi bị cấm tại khoản 4 và khoản 5 điều 17 của dự thảo như sau:

Thứ nhất: Giữ nguyên nội dung khoản 4: Kê khai không trung thực, không chính xác nội dung hồ sơ đăng ký doanh nghiệp và nội dung hồ sơ đăng ký thay đổi nội dung đăng ký doanh nghiệp.

Thứ hai: Bỏ cụm từ "Kê khai khống vốn điều lệ" trong vế đầu tiên của khoản 5 để không bị trùng với nội dung quy định cấm tại khoản 4 trên đây.

Thứ ba: Để quy định cấm tại khoản 5 hoàn thiện hơn, khoa học hơn, không còn lung túng trong cách hiểu khi quy định này được Quốc hội thông qua thì giữ nguyên của hành vi bị cấm ở vế thứ hai và thứ ba của quy phạm này là: “ không góp đủ số vốn điều lệ như đã đăng ký; cố ý định giá tài sản góp vốn không đúng giá trị."

\section{VỀ VẤN ĐỀ THỦ TỤC ĐĂNG KÝ DOANH NGHIỆP}

\section{1. Đối với vấn đề thủ tục đăng ký doanh nghiệp, theo quan điểm của Tác giả:}

Phải khẳng định rằng, một trong những quy định được đánh giá là có tính cải cách nhất của Luật doanh nghiệp 2014 là thủ tục đăng ký doanh nghiệp, trong đó Giấy chứng nhận đăng ký doanh nghiệp không còn ghi ngành nghề đăng ký kinh doanh.

Tuy nhiên, sự tiến bộ này của Luật doanh nghiệp về thủ tục đăng ký kinh doanh đã không được hiện thực hóa trong các văn bản hướng dẫn cũng như trên thực tế cấp giấy chứng nhận thành lập của cơ quan đăng ký kinh doanh cấp tỉnh thành trong suốt 5 năm qua kể từ khi luật này có hiệu lực thi hành. Cụ thể, đối với thủ tục đăng ký doanh nghiệp, Người đi đăng ký thành lập doanh nghiệp khi nộp hồ sơ đăng ký doanh nghiệp tại cơ quan đăng ký kinh doanh phải xác định mã ngành cấp 4 đối với ngành, nghề mà mình đăng ký kinh doanh. Như vậy quy định bỏ ngành nghề khi đăng ký thành lập doanh nghiệp là một lý thuyết đánh 
lừa thực tiễn, gây khó khăn không nhỏ cho cơ quan đăng ký kinh doanh cấp tỉnh thành và cho chính cả doanh nghiệp khi đi đăng ký thành lập cũng như thay đổi nội dung đăng ký thành lập doanh nghiệp. Nói cách khác, đây là một rào cản khó chấp nhận trong thực tiễn. Khi mà trong điều luật doanh nghiệp năm 2014 được Quốc hội thông qua bãi bỏ mở lối trong giấy chứng nhận đăng ký thành lập doanh nghiệp không ghi ngành nghề kinh doanh nhưng trong nghị định hướng dẫn thi hành Luật doanh nghiệp của Chính phủ lại bắt buộc Người đi đăng ký thành lập phải ghi ngành nghề kinh doanh phải xác định mã ngành cấp 4 đối với ngành, nghề mà mình đăng ký kinh doanh. Rõ ràng, những điểm vướng mắc trong thực tiễn các nhà làm luật cũng như các nhà hành pháp chưa xác định rõ tính rắc rối, rủi roc ho người đi thành lập doanh nghiệp, từ đó giảm giá trị pháp lý trong giai đoạn soạn thảo Luật cũng như trong giai đoạn triển khai áp dụng nó trong thực tiễn. Theo khảo sát của chúng tôi, trên địa bàn thành phố Hồ Chí Minh cứ 100 người đi thành lập doanh nghiệp thì đến 95 người thắc mắc về quy định bất hợp lý nêu trên. Thậm chí các doanh nghiệp họ đã có văn bản trực tiếp đề nghị cơ quan đăng ký thành lập doanh nghiệp là Sở Kế hoạch và Đầu tư không cần phải bắt buộc kê khai ngành nghề đăng kí trong giấy đề nghị đăng ký thành lập doanh nghiệp nhưng không được giải quyết. Đặc biệt, có những trường hợp hồ sơ đã nộp vào phòng đăng ký kinh doanh của Sở Kế hoạch và đầu tư và người đi thành lập doanh nghiệp cứ mặc nhiên 3 ngày làm việc sẽ nhận được giấy chứng nhận đăng ký doanh nghiệp. Tuy nhiên, sau đó thì họ nhận được thông báo từ cán bộ thu lý hồ sơ của phòng đăng ký kinh doanh trả lời phải bổ sung ngành nghề kinh doanh trong hồ sơ đăng ký thành lập doanh nghiệp thì mới được cấp giấy chứng nhận thành lập doanh nghiệp, với một lý do đơn giản là phải thực hiện theo đúng Nghị định quy định về đăng ký doanh nghiệp của Chính phủ và thông tư hướng dẫn của Bộ Kế hoạch và Đầu tư. Như vậy, trong vấn đề ngành nghề đăng ký kinh doanh hiện nay vẫn rắc rối, bất cập thiếu thống nhất giữa văn bản Luật do Quốc hội ban hành với các văn bản hướng dẫn thi hành dưới luật của cơ quan hành pháp. Nghĩa là những rào cản nêu trên đây thật sự chưa cải cách đúng nghĩa về thủ tục đăng ký kinh doanh trong nền kinh tế tihj trường ở nước ta, khi mà vẫn tiếp tục giữ quy định này trong các cơ quan hành pháp, mặc dù Luật doanh nghiệp 2014 lại không thấy có quy định.

\section{Kiến nghị:}

Để đảm bảo đúng nguyên tắc tinh thần sửa Luật doanh nghiệp để đơn giản hóa thủ tục hành chính, tạo tính cải cách, đột phá về thủ tục đăng ký kinh doanh, tạo điều kiện thông thoáng thủ tục đăng ký thành lập doanh nghiệp của công dân. Chúng tôi đề nghị Ban soạn thảo xem xét cân nhắc sửa đổi, bổ sung vấn đề ngành nghề đăng ký kinh doanh theo hướng sau đây:

Phương án một là: .Bỏ quy định "Ngành, nghề đăng ký kinh doanh không bị cấm đầu tư kinh doanh" trong quy định tại điểm a khoản 1 điều 28 của dự thảo đối với một trong những điều kiện để Doanh nghiệp được cấp Giấy chứng nhận đăng ký doanh nghiệp" Chế định này được thống nhất như sau: Điều 28. Cấp Giấy chứng nhận đăng ký doanh nghiệp

1. Doanh nghiệp được cấp Giấy chứng nhận đăng ký doanh nghiệp khi có đủ các điều kiện sau đây:

a) Tên của doanh nghiệp được đặt theo đúng quy định tại các điều 38, 39, 40 và 42 của Luật này;

b) Có hồ sơ đăng ký doanh nghiệp hợp lệ;

c) Nộp đủ lệ phí đăng ký doanh nghiệp theo quy định pháp luật về phí và lệ phí.

Phương án hai là: Gữi nguyên chể định này thống nhất trong mối quan hệ biện chứng .trong các nội dung đăng ký kinh doanh mà ban soạn thảo đã xây dựng như hồ sơ, giấy đề ngihj, giấy chứng nhận, và điều kiện đăng ký kinh odanh của người đi thành lập doanh nghiệp. Tuy nhiên bổ sung quy định rõ về thủ tục đăng ký doanh nghiệp ngay trong Dự thảo Luật lần này tại điều 29 "Nội dung giấy chứng nhận đăng ký doanh nghiệp". Nghĩa là cần quy định rõ khi đăng ký kinh doanh doanh nghiệp phải xác định mã ngành đối với ngành, nghề mà mình đăng ký trong "Nội dung giấy chứng nhận đăng ký doanh nghiệp" tại điều 29 của dự thảo, như sau:

\section{Điều 29. Nội dung Giấy chứng nhận đăng ký doanh nghiệp}

1. Tên doanh nghiệp và mã số doanh nghiệp.

2. Địa chỉ trụ sở chính của doanh nghiệp.

3. Họ, tên, địa chỉ thường trú, quốc tịch, số Thẻ căn cước công dân, Giấy chứng minh nhân dân, Hộ chiếu hoặc chứng thực cá nhân hợp pháp khác của người đại diện theo pháp luật của doanh nghiệp đối với công ty trách nhiệm hữu hạn và công ty cổ phần; của các thành viên hợp danh đối với công ty hợp danh; của chủ doanh nghiệp đối với doanh nghiệp tư nhân; họ, tên, địa chỉ thường trú, quốc tịch, số Thẻ căn cước công dân, Giấy chứng minh nhân dân, Hộ chiếu hoặc chứng thực cá nhân hợp pháp khác của thành viên là cá 
nhân; tên, mã số doanh nghiệp và địa chỉ trụ sở chính của thành viên là tổ chức đối với công ty trách nhiệm hữu hạn.

4. Ngành, nghề đăng ký kinh doanh không bị cấm đầu tư kinh doanh;

5. Vốn điều lệ.

TÓM LẠI: Có thể nói, hệ thống pháp luật quốc gia trong đó Luật doanh nghiệp có ý nghĩa quan trọng đối với việc đảm bảo quyền tự do kinh doanh nói chung và đảm bảo quyền tự do thành lập doanh nghiệp nói riêng. Sự rõ ràng, hiệu quả, toàn diện minh bạch trong các nội dung pháp luật sẽ quyết định cho sự phát triển của nền kinh tế. Từ những bất cập còn tồn tại trong thực tiễn thành lập doanh nghiệp Ban soạn thảo đã tổng hợp trong dự thảo sửa đổi Luật doanh nghiệp lần thứ ba thể hiện tính chuyên sâu hơn làm cho các quy định pháp luật hoàn thiện hơn nữa về thể chế đối với vấn đề thành lập doanh nghiệp nói riêng và pháp luật kinh tế nói chung. Thiết nghĩ, việc chú ý trọng tâm góp ý kiến cải cách liên quan đến thành lập doanh nghiệp sẽ đem lại cơ hội và môi trường phát triển bền vững cho cộng đồng doanh nghiệp, mô hình quản lý chuyên nghiệp và hiệu quả cho cơ quan quản lý nhà nước về doanh nghiệp.

\section{TÀI LIỆU THAM KHẢO}

[1]. Bộ Luật Dân sự năm 2015, NXB Sự thật năm 2016

[2] .Dự thảo sửa đổi Luật Doanh nghiệp 2014 lần thứ 3

[3] .Luật Doanh nghiệp 2014, NXB Sự thật Năm 2015

[4]. Luật số 42/2019/QH14 ngày 14 tháng 6 năm 2019 của Quốc hội sửa đổi, bổ sung một số điều của Luật Kinh doanh bảo hiểm, Luật Sở hữu trí tuệ, có hiệu lực kể từ ngày 01 tháng 11 năm 2019

[5].Nghị định 108/2018/NĐ-CP, sửa đổi, bổ sung một số điều của Nghị định 78/2015/NĐ-CP ngày 14/9/2015 của Chính phủ về đăng ký doanh nghiệp

[6]. Nghị định 78/2015/NĐ-CP ngày 14 tháng 9 năm 2015 của Chính phủ quy định chi tiết về đăng ký kinh doanh

[7].Nhận định về thủ tục thành lập doanh nghiệp ở Việt Nam của Ngân hàng thế giới năm 2019

[8]. Thực trạng thành lập doanh nghiệp ở Việt Nam hiện nay - một số bất cập và kiến nghị hoàn thiện. Ths. Hoàng

Thị Thanh Hoa và Ths.Uông Hồng Thắng

Ngày nhận bài: 06/05/2020

Ngày chấp nhận đăng: 19/08/2020 